\title{
The Role of Museum to Promote STEM Education and Teacher Interdisciplinary Training: Introducing the Experience of National Science and Technology Museum
}

\author{
Jian-Liang Lin ${ }^{1}$, Kuo-Hung Hsiao ${ }^{2}$, Li-Chun Lin $^{2}$ \\ 1 Exhibition Division, National Science and Technology Museum \\ Kaohsiung 80765, Taiwan \\ 886-7-3800089, golduser007@gmail.com \\ 2 Collection \& Research Division, National Science and Technology Museum \\ 886-7-3800089, khhsiao@mail.nstm.gov.tw, 1lc@mail.nstm.gov.tw
}

\begin{abstract}
STEM (or STEAM) and maker are gradually combined in the customized classes in Taiwan. However, the available resources of schools cannot sufficiently support multiple content and equipment. Museums can be one kind of resolutions to promote STEAM education, Maker and interdisciplinary trainings of teachers on duty. And, the teaching is the expansion of exhibition content. Here, this paper presents the scheme, process and experience of National Science and Technology Museum (NSTM in short) in Taiwan. In 2015, NSTM set up a workspace with tools and facilities for STEAM and maker educations to connect the several resources so as to establish a makers circle. The objects are teachers, students and common people, even pre-school children. Until now, NSTM collaborates with five indigenous maker groups and two neighboring universities. The museum presents 110 classes in average and holds two campaigns for announcing results at least every year. Especially, the learning records of participants will be analyzed systematically to present the personal characteristics. It is helpful for strengthening the efficiency of learning and choosing the interested ambitions in the future. In a word, the concept that the museum executes the non-customized education for the promotion of STEAM and Maker is workable.
\end{abstract}

Key words: STEM/STEAM, Maker, interdisciplinary training, non-customized education

\section{Introduction}

STEM education is an interdisciplinary learning and guides students to discover, study and resolve inquires by themselves [1]. Logic thinking and practice with systematic procedures are cultivated during the learning process. With the development of interdisciplinary education, STEM is upgraded to the next level, STEAM, through including the cultivation of art [2-4]. The next generations can adequately develop their creativity and traits by following the programs of STEAM education. This trend of teaching and learning popular in the world is more and more emphasized in Taiwan. The innovative teaching and learning will be gradually involved in the customized classes.

Maker education is another educational trend in Taiwan now. This is included the research of multiple fields and the practice. This education especially focuses on making ability, i.e., thoughts have to be realized. With the development of open source elements, the popularization of internet and the manufacture of safe machines, independent learning is encouraged and convenient. Since sharing with others is much general in accordance with the spirit of makers, problems during the process of learning and making can be resolved by others on the internet. However,

Actually, STEAM education and maker education are mixed in Taiwan. It seems not to be meaningful that educators clearly distinguish these two interdisciplinary educational ways. Furthermore, they can be combined into a systematic process of education with learning, thinking, practice and creation. Even, it will be a cycle to feedback something people learning and creating to generate new teaching. In this paper, the combined educational way is presented. The related application is practiced in the museum, not a department of customized classes. And, the experiences and results introduced.

\section{Available Customized Classes in Taiwan}

Information education, computer skills and living technology were already scheduled and emphasized, according to the available customized classes of schools. However, these available contents are not sufficient enough for meeting the challenges in the future and without the competing abilities in the world. For the information education in several elementary schools, the teaching content is to teach how to use office software. A basic requirement how to combine a computer might be a fight for some students.

As far as the living technology, a subject with multiple interesting fields, it is really a class that exists in name only. Now, several urban students can use 3D printing machine and laser machine. But, they cannot use basic tools and machines for simple repairing or creating something. As to the students in remote area or underprivileged students, the problems seem to be reversed, i.e., they can use tools, even simple machines, but they cannot understand the latest manufacturing technology (3DP, laser cutting). It is said that 3D printing and laser cutting are two of convenient manufacturing ways, but they are not the whole of living technology. Many teachers intensely promote maker education by 3DP. This situation seems to drift off course in technology education. As far as manufacturing is considered, it has to keep in our minds that we must utilize the most way to carry out our designs.

Except for the gap of resources between cities and countries, not only students but also teachers almost ignored these subjects' contents under the academic press during the time period over ten years in Taiwan. It is related to economic structure of society, not to constrain in educations. And, teaching resources are the first requirements before talking about the learning of students. At present, in promoting the 
STEAM and maker education in Taiwan, such a situation results in that teachers corresponding to these subjects ignored for a long time are not sufficient. The teachers or pre-teachers should take interdisciplinary trains to have multiple research backgrounds or be familiar with their original skills and techniques. Actually, they are pioneers of learning. The museum can be the key role to provide the professional trains required for STEAM and Maker educations except for universities. Owing to the opening model of museum, the learners are diverse, such as teachers, students, pre-children, public and retired people.

\section{The Conceptual Model of Color Palette}

In the wheel model of STEAM education by P.W. Kim in 2016, it is presented that STEAM education should be extended to the humanities field including history, geography and bibliography. And, this model can be realized by the Performing Project Method [5]. Here, through this model and the existing research [6], the conceptual model of the museum for promoting STEAM and maker education can be developed as a color palette, as shown in Fig. 1. This conceptual model is appropriate for the design of classes and the building of implement structure.

Focusing on the educational concept of color palette, the center should be the core concepts or topics of a teaching plan. The content of teaching plan must involve several fields and can be generated by the results of interdisciplinary survey. In this conceptual model, the field of history $(\mathrm{H})$ and philology $(\mathrm{P})$ should be considered except for five fields of STEAM $(\mathrm{STEAM}+\mathrm{H} / \mathrm{P})$. And thus, the teaching plans are executed through common classes, activities, exhibitions and interdisciplinary trainings for teachers. The concepts of Maker are added during the execution process of teaching plans, i.e., practice is a critically important. The learners have to make somethings. The ability of making is claimed and trained. Once the learners understand the teaching content thoroughly, it is possible that the related teaching aids are developed. The learners can generate more creative teaching plans. Therefore, the cycle of makers can be built and the educational concept of color palette for combing the fields of STEAM, history and philology and maker spirit.

Ancient locks for example, the locks are one kind of important collections in NSTM. The research of ancient locks involves science (spring and stiffness of materials), technology (casting, sculpture), mechanical engineering (mechanism design and manufacturing) and art (pattern, shape). Because of the characteristics of cultural relics, the historical development and the meaning of patterns and shapes can be studied. The styles of locks from different areas are diverse. The related meaning of locks can be investigated by the survey of historical literatures further. And thus, the field can be extended to history and philology. The research information is concluded to design the corresponding teaching plans, build the prototypes for exhibition, and develop the teaching aids, as shown in Fig. 2 $[7,8]$.

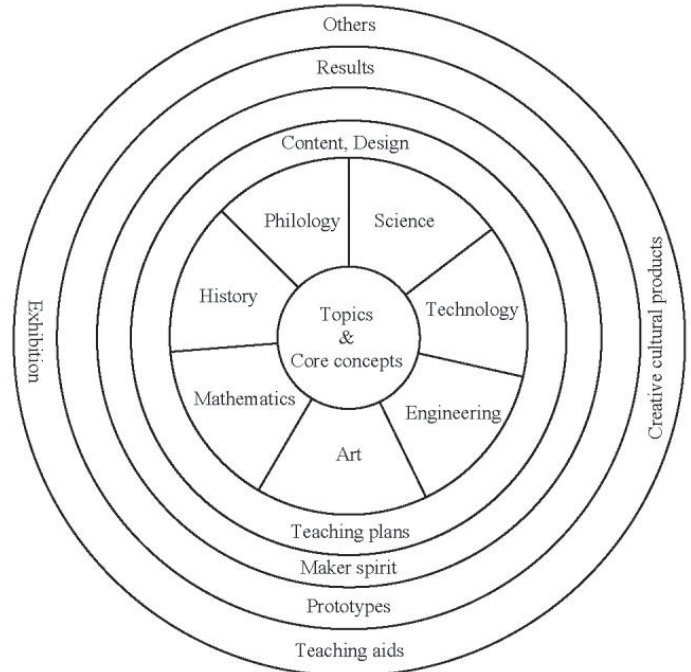

Fig. 1 Educational concept of color palette model

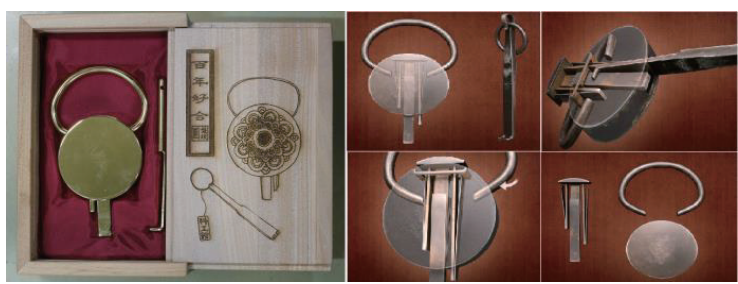

Fig. 2 Developed products of ancient lock in NSTM

\section{An Implement Model of NSTM}

\section{A. Available Structure of True Dreamland in NSTM}

In 2015, NSTM built a workspace called true dream land to exactly promote the education of STEAM or Maker. The workspace like a small factory have a wooden working room, a metal working room, a welding room, an integrated processing room, an achievements exhibition zone and a study room for discussion and teaching. An experience zone and a wooden working zone especially for preschool children were added in 2016. Various kinds of equipment, from the field of technology to the field of technique, are gradually increasing with the requirements of makers and classes. The scheduled structure of maker space in NSTM at present and introduced as follows:

(1) $\mathrm{STEAM}+\mathrm{H} / \mathrm{C}$ and Maker classes

Students, corresponding to STEAM and Maker classes in NSTM, are unconstrained because of the role and missions of museum. In basic, NSTM presents several kinds of systematic classes based on the concepts of color palette. These classes might include several directions of STEAM, and satisfy the following trend of customized classes. Finally, the learners can be lead to be interdisciplinary makers by systematic process of teaching. It is a cycle for the concept of color palette that they might develop their creative designs as teaching plans or prototypes.

(2) Interdisciplinary training of teachers

As mentioned above, the execution of STEAM and Maker educations in customized classes in schools is a problem. Based 


\section{Recent Developments on Information and Communication Technology (ICT) Engineering- Meen, Yang \& Zhao ISBN: 978-981-14-2136-5}

on the research [9], it is workable that NSTM provide the corresponding trainings to available teachers who might not be familiar with interdisciplinary research or latest technologies. As a result, they would not be back to universities or study the related content by themselves online. The most important is that they have chances to create something practically so as to be familiar with some skills or machines again. The content of interdisciplinary trainings of teachers is a kind of STEAM classes.

(3) Fostering seed teachers in NSTM

Except for the researchers and staffs of the museum, NSTM provides several kinds of trainings and classes through several ways, including the invitation of experts and the cooperation of professional communities or companies for education. However, the human resources of teaching are not sufficient for the increasing requirements of classes about the latest technology. NSTM gradually fosters its seed teachers based on the long-term plan. Most of these seed teachers are the oncoming teachers by considering teaching ability and experiences. The qualified seed teachers have to finish a systematic training process like taking a course of university, especially for the ability of practice and the application of multiple research fields.

(4) A system of users' learning record

In order to generate a series of effective learning, the museum will build a system of learners to conclude personal characteristics and abilities through analyzing learning records. The system is prepared for all learners, including seed teachers and available teachers for interdisciplinary trainings. Based on this learning record, the classes in the museum can be systematically developed from beginner lever to advancer level and classified by following the directions of STEAM education. Also, the system is the application of education concept of color palette.

(5) Integration of resources

Since the fields of STEAM and maker educations are extensive, the required resources, the human resource of teaching, tools and machines, are considerable. Except for universities, there are several of off-campus experts, maker groups, or companies of education in Taiwan. The museum cooperates with these targets to integrate the available education resources. The content of learn can be effectively expanded. Simultaneously, the museum can collect the like-minded educators to achieve the cycle of makers.

(6) Developments of teaching plans and models

Except for the teaching and learning of participants, the development of teaching aids and plans related to the content of STEAM and maker educations. With the available implement structure in the museum, the complete teaching plans with STEAM and maker content are systematically generated by existing teachers or people who are in or after the trainings. Furthermore, the corresponding teaching aids or models are presented. These innovative contents of teaching keep on updating the teaching database of STEAM educations to follow the latest information of technology. It is a quite effective way to truly practice maker by creating teaching aids or models.

\section{B. Results}

Until now, the true dreamland holds on thirty classes in average each three months. These classes are the training of techniques or the integration of multiple fields, such as the wooded creation, the application of 3D printer and laser cutting, basic information of IoT (Internet of object), programing and electrical control, creation of jewelry. Some classes correspond to the available exhibitions in the museum, i.e., the learning is regarded to continuation of the exhibitions, the teaching and exhibition of IoT for example, as shown in Fig. 3. Some classes are the Cultural and Creative Products. As to the integration of exterior resources, the true dreamland cooperates with five universities near the museum, six maker groups, and one company about STEAM education.

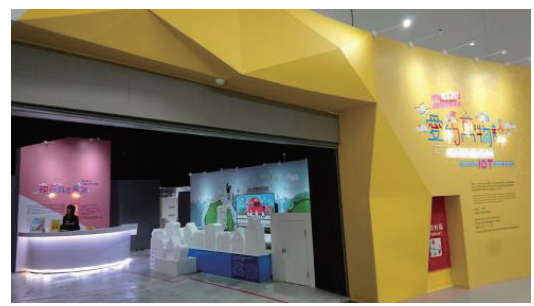

(a) Annual exhibition of IoT

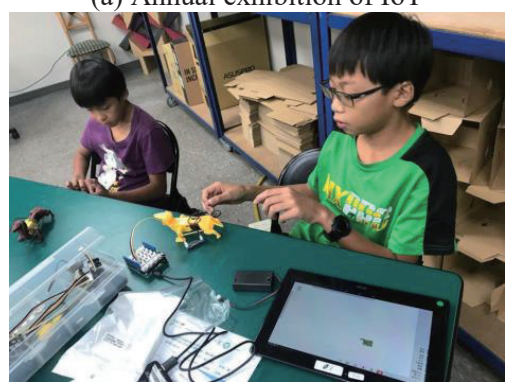

(b) Teaching record of IoT

Fig. 3 Annual exhibition and related teaching of IoT

There are two presentations for announcing results of STEAM and maker educations in NSTM at least. The prototypes by students or retraining, teachers or makers can be demonstrated to introduce their innovative concepts and creative designs. Fig. 4 is the teaching record and the wooden-creation exhibition. This class for common people is held eight hours once week for 10 week. The teacher is a carpenter with professional licenses. The content includes the operation of machines and tools for wooden work. The designs of prototypes depend on students themselves. Therefore, following the same teaching of techniques, the products resulting from different students are variable.

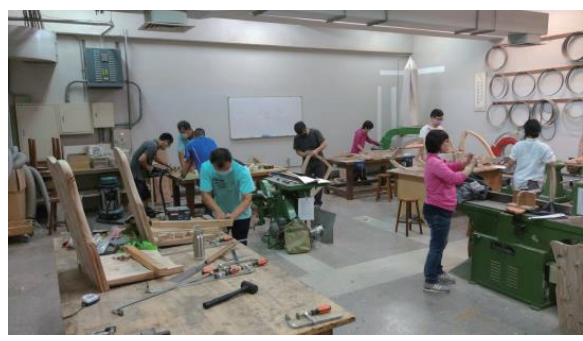

(a) Teaching record 


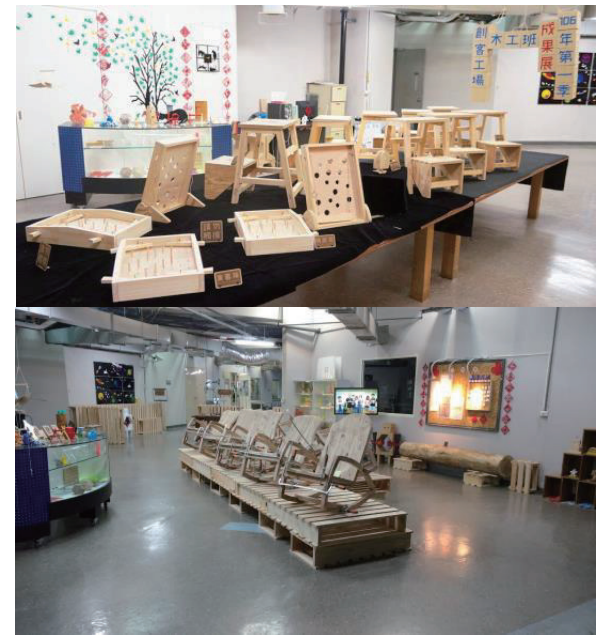

(b) Wooden-creation exhibition

Fig. 4 The wooden-creation exhibition and teaching record

Furthermore, the important activity of NSTM is the annual Maker festival. Since the establishment of True Dreamland, NSTM held on maker festivals respectively in 2015 and 2016, as shown in Fig. 5. The schools, companies, individual and commercial makers are attended to the festivals and displayed their results with innovation and educational concepts. Simultaneously, NSTM cooperated with these participants to take place related workshops. It is much effective to connect the museum and the exterior intuitions and integrate the sources so as to promote STEAM education in museums.

\section{Conclusions}

Considering the wheel model of STEAM education, the educational concept of color palette model combing the interdisciplinary learning and maker spirit is presented. The content of STEAM education is extended to history and philology so as to understand the historical development and the historical literatures related to the teaching topic. This concept is developed especially for the learning of ancient machinery, technology or techniques. In the content of teaching plans following the model, the learners in the model have to train their ability of making. The physical models like prototypes, teaching aids, cultural and creative products can be generated and feedback to the updating of teaching plans. Finally, the related plans and structure of promotion is executed in the museum. The model is proved by the current execution results of the museum.

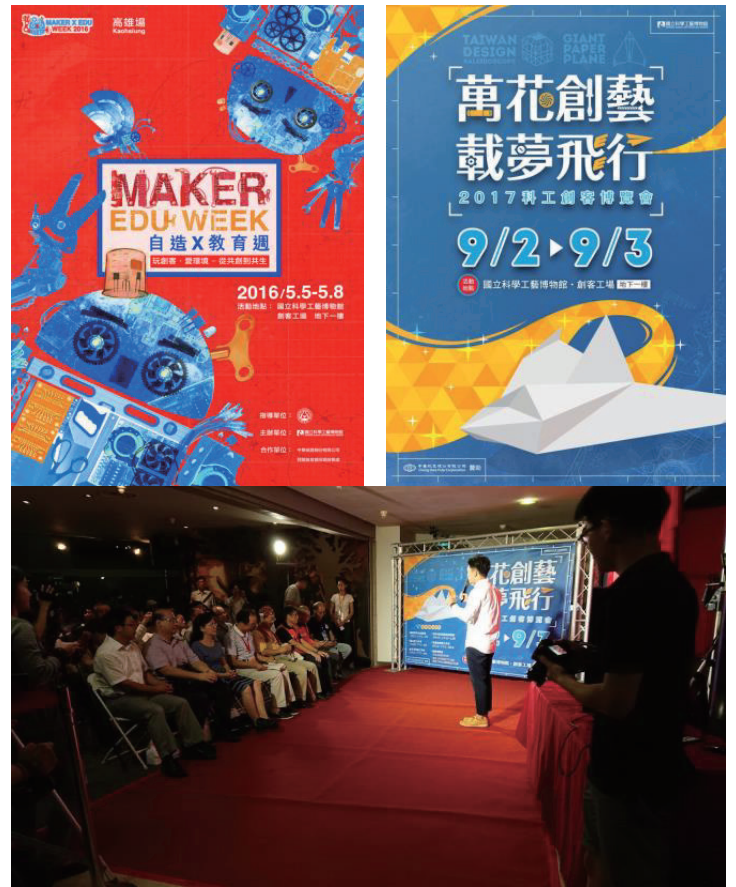

Fig. 5 Annual festivals of maker (2016 \& 2017)

\section{Acknowledgements}

The authors are grateful to the Ministry of Science and Technology (Taipei, Taiwan) under Grant: MOST 105-2218-E-359-001 and MOST 106-2221-E-359-001 for the financial support of this work.

\section{References}

[1] H.B. Gonzaler, J.J. Kuenzi, "Science, Technology, Engineering, and Mathematics (STEM) Education: A Primer" Congressional Research Service, 2012. Retrieved Dec. 2017.

[2] S.R. Pomeroy, "From STEM to STEAM: Science and Art Go Hand-in-Hand," Scientific American, 2012. Retrieved Dec. 2017.

[3] J.M. Eger, "National Science Foundation Slowly Turning STEM to STEAM," Huffington Post, 2011. Retrieved Dec. 2017.

[4] A. Jolly, "STEM v.s. STEAM: Do the Arts Belong?" Education Week: Teacher, 2014. Retrieved Dec. 2017.

[5] P.W. Kim, "The Wheel Model of STEAM Education Based on Traditional Korean Scientific Contents, “Eurasia Journal of Mathematics, Science \& Technology Education, Vol.12(9), p. 2353-237, 2016.

[6] H.B. Kim, D.H. Chae"The Development and Application of a STEAM Program Based on Traditional Korean Culture," Eurasia Journal of Mathematics, Science \& Technology Education, Vol.12(7), p. 1925-1936, 2016.

[7] H.S. Yan, R.J. Lee, K.H. Hsiao, Shi De Qi Suo - the special issue of locks exhibition (in Chinese), National Science and Technology Museum in Press, 2012.

[8] H.S. Yan, Gu Zao Zhong Guo Suo Ju Zhi Mei (in Chinese), National Cheng Kung University in Press, Taiwan, 2015.

[9] H.J. Park, S.Y. Byun, J. Sim, H. Han, Y.S. Baek, "Teachers' Perceptions and Practices of STEAM Education in South Korea." Eurasia Journal of Mathematics, Science \& Technology Education, Vol.12(7), p. 1739-1753, 2016. 